\title{
Frente al Tabaquismo
}

\section{Sr. Editor:}

Convengo con nuestro Presidente, en su artículo editorial "Y frente al tabaquismo, ¿podemos hacer más?", que los abrumadores datos estadísticos sobre la gran epidemia tabáquica, así como sus consecuencias directas y presentes sobre la salud de nuestros pacientes, deberían hacernos recapacitar sobre la prioridad que realizamos en nuestras consultas ante este grave problema de salud.

Pero ¿de qué depende que un profesional sanitario tome una iniciativa de acción (priorice y actúe) sobre cualquier problema de salud y particularmente sobre el tabaquismo? Indudablemente, de la percepción subjetiva de la importancia (gravedad), de los conocimientos que tiene sobre este problema, sobre los instrumentos y tratamientos existentes y su eficacia (habilidades adquiridas), pero también de la obtención de resultados tangibles (curación) y del apoyo de la sociedad (percepción social frente al tabaquismo), especialmente de los poderes públicos (acción pública frente al tabaquismo). Es decir, creer que el tabaquismo, tanto activo como pasivo, es una enfermedad con entidad propia (causa daño) además de ser "factor de riesgo". Creer en los tratamientos, tanto farmacológicos como no farmacológicos, y aplicarlos, evitando la discriminación frente a otros factores de riesgo cardiovascular como la hipertensión o el colesterol (tratar el tabaquismo es cuatro veces más coste-efectivo que el de la hipertensión arterial y trece veces más efectivo que el de la hipercolesterolemia). Creernos que con nuestra actuación día a día salvamos vidas (la mortalidad por tabaquismo es del $50 \%$ ).

En este sentido, la Sociedad Castellano-Manchega de Medicina de Familia y Comunitaria viene desarrollando el Programa Atención Primaria sin Humo en los Centros de Salud de toda la Comunidad, entre cuyos objetivos están la formación y homogeneización de la atención en tabaquismo.

En cuanto a la percepción social, tras la aplicación de la Ley 28/2005, de 26 de diciembre, de medidas sanitarias frente al tabaquismo y reguladora de la venta, el suministro, el consumo y la publicidad de los productos del tabaco, no hay duda de que "algo se esta moviendo" (a pesar de las limitaciones de la Ley) y los profesionales sanitarios tenemos algo que aportar nos guste o no: nuestra función modélica, no fumando en las entradas de los edificios sanitarios, o mejor aún, dejando definitivamente de fumar o pidiendo la creación de más espacios sin humos.

Respecto de la acción de los poderes públicos, son seis las intervenciones rentables para el control del tabaquismo (The ASPECT Consortium, Tobacco or Health in the European Union, Luxembourg: Directorate-General for Health and Consumer Protection, European Commission, 2004):

- Aumento del Precio con impuestos más altos sobre los cigarrillos y otros productos de tabaco.

- Prohibiciones de la promoción y publicidad de todos los productos de tabaco, logos y marcas, en todos los ámbitos.

- Prohibiciones/restricciones de fumar en público y lugares de trabajo.

- Mejor información de consumidor incluyendo campañas públicas de información, con cobertura en todos los medios de comunicación.

- Advertencias, directa en etiquetas y el embalaje cigarrillo y otros productos de tabaco.

- Tratamiento para ayudar a fumadores incluyendo el acceso a medicaciones.

Algunas de ellas desarrolladas en nuestro país con diferencias entre Comunidades Autónomas. Debemos poner en juego nuestra función de presión exigiendo a nuestra Comunidad Autónoma la financiación de los medicamentos sin restricciones, proponiendo medidas para universalizar los espacios sin humo y reclamar el cumplimiento estricto de la Ley actual.

En resumen, a las funciones preventivas, educativas y curativas desarrolladas magníficamente por nuestro Presidente en su editorial no sólo podemos sino que debemos añadir la función modélica y la función de presión.

Ángel García Imbroda

Coordinador del Grupo de Abordaje del Tabaquismo de SCAMFyC.

E-mail agarciai@sescam.jccm.es 